\title{
Objectives and Progress on Ground Vibration Testing for the Ares Launch Vehicles
}

\author{
Margaret L. Tuma, Ph.D. ${ }^{1}$, Bruce R. Askins ${ }^{2}$ \\ Ares Flight \& Integrated Test Office (FITO), Marshall Space Flight Center, Huntsville, AL 35812 \\ Donald J. Chenevert, $\mathrm{PhD}, \mathrm{PE}^{3}$ \\ Ares FITO, Marshall Space Flight Center, Huntsville, AL 35812
}

BC
$C S M$
$D A S$
$D C R$
$D V T$
$E D S$
$E T$
$F E M$
FITO
FS
GN\&C
GSE
GTA
GVT
HDS
IU
IVGVT
KSC
LAS
LES
LH

$=$ Boundary Condition

$=$ Command/Service Module

$=$ Data Acquisition System

$=$ Design Certification Review

$=$ Dynamic Vehicle Test

$=$ Earth Departure Stage

$=$ External Tank

$=$ Finite Element Model

$=$ Flight and Integrated Test Office

$=$ First Stage

= Guidance, Navigation, and Control

$=$ Ground Support Equipment

$=$ Ground Test Article

$=$ Ground Vibration Test

$=$ Hydrodynamic Support System

$=$ Instrument Unit

$=$ Integrated Vehicle Ground Vibration Test

$=$ Kennedy Space Center

$=$ Launch Abort System

$=$ Launch Escape System

$=$ Liquid Hydrogen

\section{Nomenclature}

\begin{tabular}{|c|c|}
\hline$L O X$ & $=$ Liquid Oxygen \\
\hline MECO & $=$ Main Engine Cut-Off \\
\hline MSFC & $=$ Marshall Space Flight Center \\
\hline MUF & $=$ Model Uncertainty Factor \\
\hline MVGVT & $=$ Mated Vertical Ground Vibration Test \\
\hline NASA & 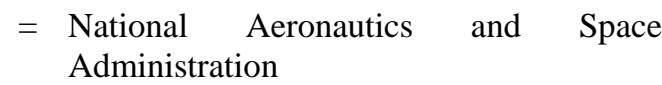 \\
\hline ORI & $=$ Operational Readiness Inspection \\
\hline$P D R$ & $=$ Preliminary Design Review \\
\hline$R G A$ & $=$ Rate Gyro Assembly \\
\hline$R M$ & $=$ Redundancy Management \\
\hline$S M E$ & $=$ Subject Matter Expert \\
\hline SMTAS & $=$ Shuttle Modal Test and Analysis System \\
\hline$S R B$ & $=$ Solid Rocket Booster \\
\hline SSME & $=$ Space Shuttle Main Engine \\
\hline STE & $=$ Special Test Equipment \\
\hline$T S$ & $=$ Test Stand \\
\hline TVC & $=$ Thrust Vector Control \\
\hline US & $=$ Upper Stage \\
\hline USE & $=$ Upper Stage Engine \\
\hline
\end{tabular}

\section{Introduction}

$\mathrm{M}$ ost launch and space vehicles, as well as aircraft, undergo dynamic testing, also known as modal testing or ground vibration testing (GVT). Such testing is conducted to validate pre-test finite element models (FEMs) used for analyzing and verifying loads. The testing confirms the vehicle's modal characteristics (natural frequencies, mode shapes, and damping). It also supports guidance, navigation, and control (GN\&C) analysis by providing test data to reduce uncertainty in models. Subsystem objectives are obtained during dynamic testing such as determining thresholds for minimum vehicle frequencies and confirming vehicle responses to GN\&C control sensors and thrust locations.

Without test-calibrated integrated vehicle ground vibration test (IVGVT) models, the model uncertainty factor (MUF) used in verification loads and levels are not updated and remain at earlier phases of the design. This can translate into increased mass margins. IVGVT can permit structural loads to be better understood and modeled. With the IVGVT data the structural design of the Ares vehicle can become more efficient, thus permitting improved mass margins. Furthermore, poorly understood vehicle modes also can cause vehicle instability due to incorrect modeling and boundary conditions and understanding of vehicle interfaces. If model uncertainties are too large, GN\&C stability requirements can either not be met or GN\&C can become more complicated.

\footnotetext{
${ }^{1}$ Manager, Structural, Environment, and Vibration Testing

${ }^{2}$ Ares I-X Project Integration Manager

${ }^{3}$ Deputy, FITO Structural, Environment, and Vibration Testing /IVGVT Deputy Lead
} 
The Aerospace Corporation conducted a study of 47 launch and space vehicle test programs ${ }^{1}$. In all but one program, the analytical models required updating prior to final vehicle deployment. The study's authors concluded that they were "not aware of a single analytical model of complex structure that has had acceptable agreement with its mode survey test data before adjustment; significant changes in loads from analytical to test-verified model.,"

Failure to conduct such testing often has catastrophic consequences. The Delta III launch vehicle was destroyed on its maiden launch due to the control system software correcting a 4 hertz oscillation that would have smoothed on its own without correction. Designers had relied on known Delta II vehicle responses even though the Delta III launch vehicle had a significantly different configuration, with an increased-diameter first stage fuel tank, a shorter length, two additional solid rocket motors, and a new second stage engine fueled by liquid oxygen/liquid hydrogen $\left(\mathrm{LOX} / \mathrm{LH}_{2}\right)$. Based on the heritage Delta II system modes, the Delta III control software corrected a vehicle mode (oscillation) that did not require correction. Had the program conducted dynamic testing on the Delta III, it is likely this mode would have been understood and the control software adjusted to accommodate it. $^{3}$

Similarly, the Ariane 5 was lost on its inaugural flight due to a lack of understanding of the vehicle's new engine nozzle and a decision by management not to compensate by adding additional safety margins into the vehicle's design and testing. The loss of the satellite payload resulted in the need for Arianespace to conduct a further demonstration flight with no payload before another paying customer would sign up to use the launch system. ${ }^{4}$

More recently, the commercially developed SpaceX Falcon 1 suffered a partial failure on its second test flight in March 2007. The launch went well until separation of the first and second stages. The first stage bumped the engine bell of the second stage engine as the interstage separated. A circular coning oscillation began and increased in amplitude causing the vehicle to roll. This ultimately produced a vehicle roll that caused the LOX tank to slosh due to the amplified oscillation. LOX tank slosh increased the oscillation, which would normally be compensated for by thrust vector control (TVC). The increased oscillation caused the TVC to overcompensate the correction, which in turn led to premature burnout of the second stage engine and a failure to meet mission objectives. Perhaps some modal characteristics of the Falcon 1 vehicle were not well understood if a bump could excite a mode that would persist and ultimately doom the mission. Falcon 1 is an example of the worst modal attributes coupling together (natural modes, slosh modes), leading to TVC overcompensation and perhaps failure of other systems to respond. More ground testing, including dynamic testing, could have helped identify these modes prior to launch, ensuring better characterization and design of the structural and slosh modes and the vehicle ability to control them.

The size of NASA launch vehicles necessitates extensive planning to ensure the vehicle and facility meet requirements not only for good test results but for the safety of those setting up and conducting the test. NASA is currently developing the next generation of launch vehicles - the Ares I crew launch vehicle and the Ares V cargo vehicle-along with the Orion crew exploration vehicle. Both Ares vehicles will require a GVT to validate analytical models to support loads and GN\&C modeling.

The Saturn and Space Shuttle programs both performed scale model dynamic tests. Saturn used a $1 / 10^{\text {th }}$ scale model. Shuttle used a $1 / 4$ scale model. Ares I analysts have determined that Ares I will not require a subscale model due to its simple in-line configuration and payload and because NASA now uses faster, more accurate computational tools. While useful in developing designs for the earlier projects, modern tools allow Ares I to omit the cost and time required to perform scale model testing.

Planning for the Ares I/Orion Integrated Vehicle GVT (IVGVT) has been ongoing since the inception of the Constellation Program. This planning draws heavily on the historic data archived in NASA libraries for Saturn V and Space Shuttle dynamic testing in the dynamic test stand at Marshall Space Flight Center (MSFC). The IVGVT has already conducted a preliminary Subject Matter Expert (SME) review to obtain the evaluation of experts from both the Saturn and Shuttle GVT projects. This availability of historic records and professional authorities with hands-on GVT experience has been a tremendous aid in IVGVT planning. A second subject matter expert (SME) review is planned prior to the Ares I Preliminary Design Review (PDR).

While not an objective of dynamic testing per se, the dynamic test in TS 4550 represented the first time the entire Saturn V and Space Shuttle vehicles were stacked. It will be the same with Ares I. It is an excellent opportunity to perform a path-finding vehicle stacking activity prior to delivery to the Kennedy Space Center (KSC) for launch preparations.

\section{Saturn V}

NASA planned and executed a GVT during the Saturn V program, called Dynamic Vehicle Test (DVT) at the time. The test was performed on a full-scale test article to determine the structural dynamic characteristics for flight control system design and to verify the vehicle's structural integrity. The test article was built to flight article 
specifications. Deviations from these specifications were built in to ensure that the overall dynamic response of the vehicle was not changed. ${ }^{5}$

The Saturn V vehicle consisted of three booster stages, the instrument unit (IU) and the payload. Fully fueled, the vehicle weighed approximately six million pounds, was 365 feet tall, and was 33 feet in diameter at the base. Deionized dichromate water was used to simulate the propellant, liquid oxygen (LOX) and RP-1, in the first stage as well as the simulant for LOX in the second and third stages. Due to the difficulties of adequately simulating liquid Hydrogen $\left(\mathrm{LH}_{2}\right)$, the $\mathrm{LH}_{2}$ tanks were left empty in the second and third stages for lateral testing and were weightsimulated with water for longitudinal and roll testing. ${ }^{6}$

Test Stand 4550 (TS 4550) was built at MSFC during 1962-1964 to perform dynamic testing for the Saturn program. Due to the very large size of the Saturn V vehicle, TS 4550 is 360 feet high. The 200-ton stiff-leg crane on top of the building adds 64 feet to the overall height. Platforms capable of folding back and away from the test article were built at 24 foot levels providing access to the vehicle. ${ }^{7}$ The vehicle was handled in the stand by derrick cranes installed on the roof and about halfway up the exterior of the stand. ${ }^{8}$
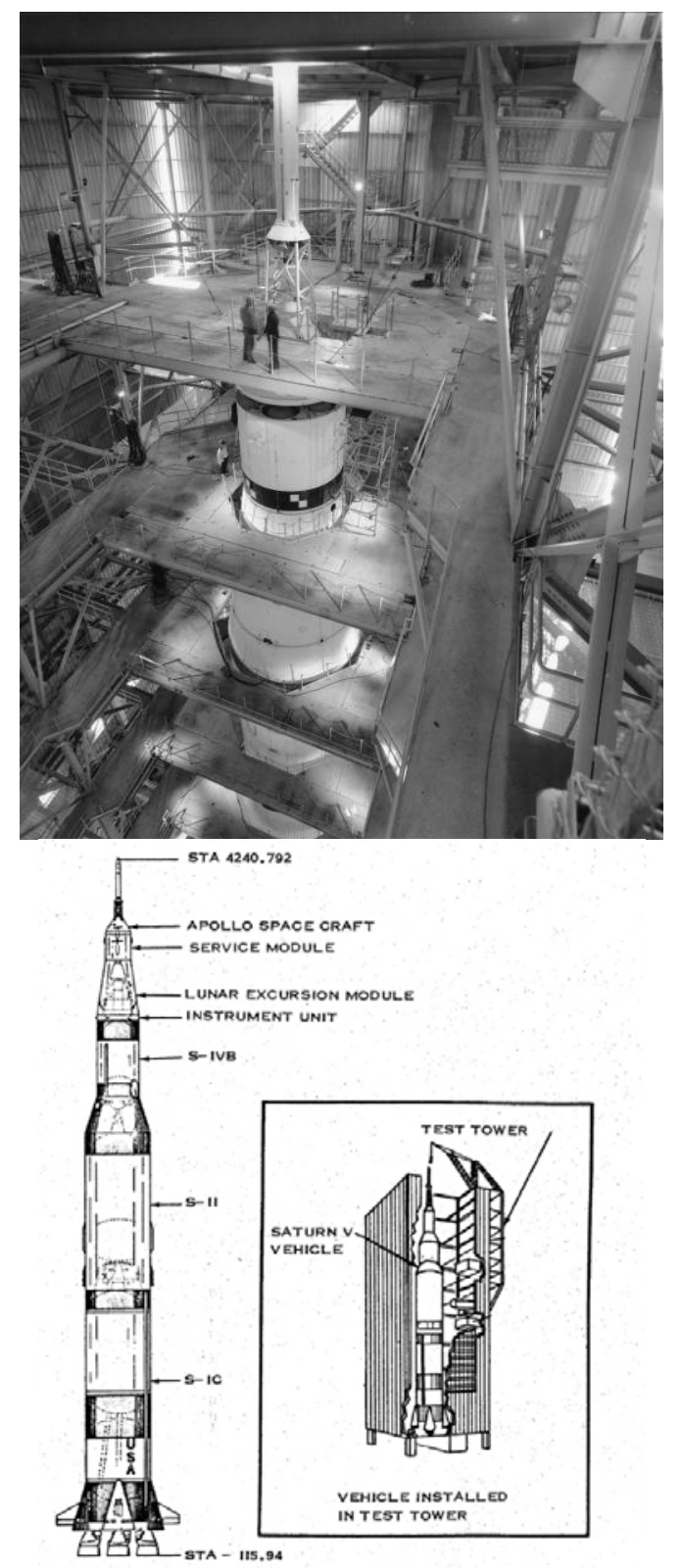

Figure 1 - Saturn V test article and installed in TS 4550 
The suspension system required to simulate free flight was a particular challenge. Suspending the vehicle by cables would not work, as the cables resonate at frequencies similar to that of the vehicle which might have complicated or invalidated test results.

NASA developed a state-of-the-art suspension system to simulate the free-free boundary conditions of flight. The hydrodynamic support system (HDS) consists of oil bearings and vertical gas springs for lateral and roll stability (Figure 2). Oil under pressure was pumped between flat contacting surfaces to provide a near-frictionless support. This system transmits the heavy vehicle load directly to the ground, enabling the support mass to be relatively small. ${ }^{9}$ The HDS units and system were so effective that the entire six-million-pound vehicle could be excited in its low frequency suspension modes by two people pushing the fins on the first stage, deflecting the vehicle as much as two inches. ${ }^{10}$

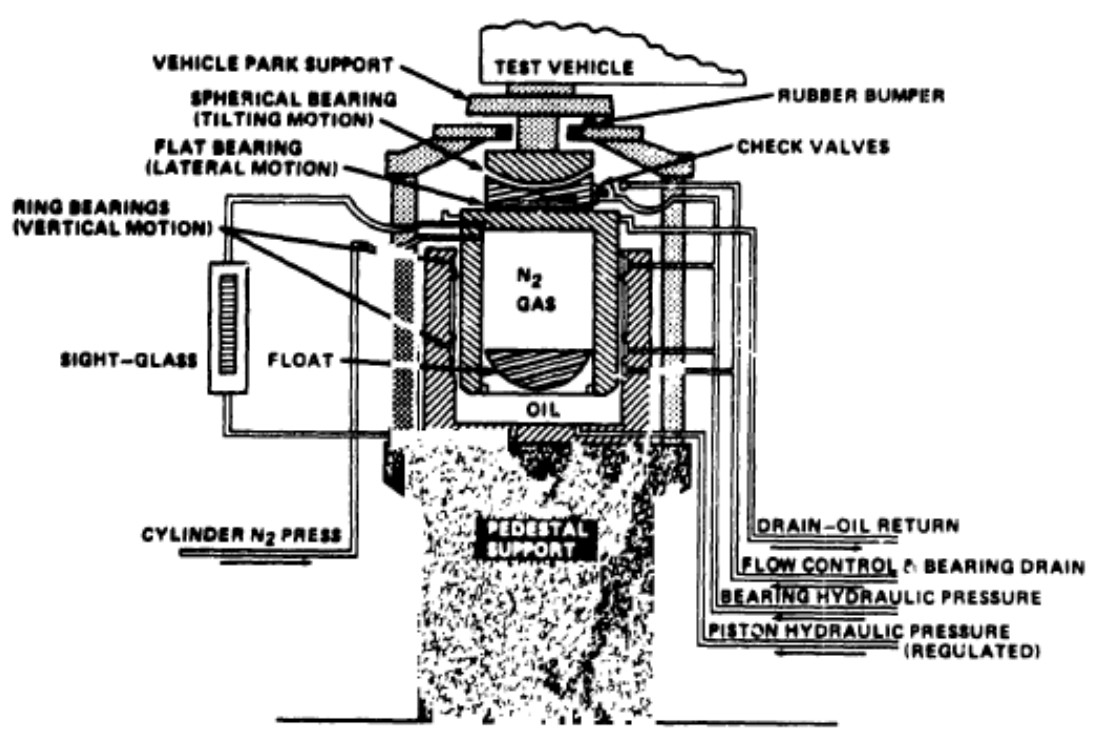

Figure 2 - Hydraulic Support System (HDS)

Lateral support of the vehicle was provided by two sets of lateral stabilizing springs. These springs were located as close to the mean nodal points as possible to minimize their impact on the overall bending modes of the vehicle. An upper stabilizing system of 16 springs was attached tangentially to provide roll restraint and keep the vehicle centered. ${ }^{11}$

The excitation consisted of a thruster system with a single four-inch single amplitude linear stroke with 20,000 pounds of output. It was eventually determined that the four-inch stroke was not required and that a 0.5 -inch stroke would suffice. The initial requirement was based on an excitation of sufficient amplitude at the sensor point to accurately determine mode shapes with available instrumentation. However, due to improvements in instrumentation sensitivity and less-than-expected modal damping, the lower stroke option would have been adequate. $^{12}$

Instrumentation consisted of accelerometers, rate gyros, pressure sensors and strain gages. A typical test used 120 sensors feeding directly to the Data Acquisition System (DAS). The DAS automatically controlled the frequency sweeps and frequency increment changes. To record or check data, the DAS used three cycles at 900 data points per second from all the sensors simultaneously.

The DVT tested three configurations of the Saturn V. Configuration I consisted of the S-IC first stage, S-II second stage, S-IV third stage, IU, Command/Service Module (CSM) and Launch Escape System (LES). Configuration II included the S-II second stage, S-IV third stage, IU, CSM and LES. Configuration III included the S-IVB-D third stage, IU, CSM, and LES. All configurations tested both the ignition and burn out conditions of the fuel tanks.

Dynamic testing was conducted on the Saturn V test vehicle between October 1966 and August 1967. A series of test were performed, including force linearity, ring-out damping and ring mode. The force linearity test excited the vehicle at three different force levels at each resonant frequency to determine nonlinear characteristics of the vehicle. The first four flexible mode resonant frequencies and measurement of the logarithmic decay of response to 
determine sensor damping when force was suddenly removed was measured by the ring-out damping test. The ring mode test was an incremental frequency sweep to determine the IU ring mode activity. ${ }^{13}$

The mathematical model developed during pre-test analysis was verified by the dynamic test and used to analyze the flight vehicle and account for mass and stiffener differences. Generally, the correlation between test results and this model were very good. A major difference, however, was found at the flight gyro cold plate in the IU. The control gyro was located on the upper half of this plate, which had a higher slope than the lower half. This made the analytical flight control parameters marginal. This finding resulted in the relocation of the control gyro to the lower half of the plate where it correlated well with analytical predictions. ${ }^{14}$

The following table summarizes the major findings and likely consequence found during the Saturn V DVT. ${ }^{15}$

Table 1. Dynamic vehicle testing helped identify several critical issues during Apollo that could have resulted in loss of mission or crew.

\begin{tabular}{|l|l|l|}
\hline \multicolumn{1}{|c|}{ Problems Discovered } & \multicolumn{1}{c|}{ Hardware Impacted } & \multicolumn{1}{c|}{$\begin{array}{c}\text { Consequences if Not } \\
\text { Discovered }\end{array}$} \\
\hline $\begin{array}{l}\text { Design deficiency in the SPS } \\
\text { tank supports. Unexpectedly } \\
\text { high local resonant coupling was } \\
\text { detected between the SPS and its } \\
\text { bulkhead support. }\end{array}$ & $\begin{array}{l}\text { The upper support bracket for the } \\
\text { SPS tanks was redesigned to } \\
\text { eliminate a strong tank cantilever } \\
\text { mode. }\end{array}$ & $\begin{array}{l}\text { Hardware failure resulting in loss } \\
\text { of mission and possible crew loss. }\end{array}$ \\
\hline $\begin{array}{l}\text { High LOX and fuel dynamic } \\
\text { tank bottom pressures. These } \\
\text { pressures were under-predicted } \\
\text { by a factor of 2. The significance } \\
\text { of these pressures was not } \\
\text { understood until after pogo } \\
\text { occurred on AS-502. }\end{array}$ & $\begin{array}{l}\text { The higher tank pressures } \\
\text { contributed to the S-IC pogo } \\
\text { accumulator hardware design. }\end{array}$ & $\begin{array}{l}\text { Potential loss of vehicle and crew } \\
\text { due to pogo. }\end{array}$ \\
\hline $\begin{array}{l}\text { High 18 Hz S-IC Crossbeam } \\
\text { mode gains. DTV data showed } \\
\text { that an accumulator should not be } \\
\text { used on the inboard engine. }\end{array}$ & $\begin{array}{l}\text { Elimination of a planned inboard } \\
\text { engine accumulator. }\end{array}$ & $\begin{array}{l}\text { Potential loss of vehicle and crew } \\
\text { due to pogo between the } 18 \mathrm{~Hz} \\
\text { accumulator mode and the } 18 \mathrm{~Hz} \\
\text { crossbeam mode. }\end{array}$ \\
\hline $\begin{array}{l}\text { Local rotation of the flight gyro } \\
\text { support plate. Vehicle dynamic } \\
\text { shears and moments deformed the } \\
\text { support plate. The math model } \\
\text { under-predicted this deformation } \\
\text { by 135\%. }\end{array}$ & $\begin{array}{l}\text { The gyros were relocated to the } \\
\text { bottom of the support plate where } \\
\text { the local rotation was much less. } \\
\text { This required wire harnesses of } \\
\text { new length. The flight control } \\
\text { filter network was redesigned. }\end{array}$ & $\begin{array}{l}\text { Flight control instability resulting } \\
\text { in loss of vehicle. }\end{array}$ \\
\hline
\end{tabular}

\section{Space Shuttle}

NASA authorized the development and manufacturing of the National Space Transportation System, commonly called the Space Shuttle, in 1972. The Space Shuttle launch vehicle consists of the orbiter, a winged vehicle capable re-entry and controlled landing as a reusable craft. At launch, the orbiter is mated to an external tank (ET) that supplies the $\mathrm{LOX} / \mathrm{LH}_{2}$ propellant to the orbiter's three main engines. Two reusable solid rocket boosters (SRBs) provide additional power at launch. The launch assembly is 184 feet tall and 122 feet long with a wing span of 78 feet. The launch vehicle weighs 4.5 million pounds at liftoff (weight may vary depending on payload). On the reentry runway, the orbiter is 57 feet tall from the landing gear to the top of the vertical stabilizer. The STS can lift a payload of 35,000 pounds to orbit. The orbiter can carry up to seven crew.

The Space Shuttle is the first reusable space vehicle and as such represented new challenges to design and analysis due to the coupled interaction of the four-body configuration (orbiter, solid rocket boosters and external tank) with many joints and local load paths. Viscoelastic effects were an added complexity due to the solid rocket boosters (SRBs) and their unsymmetrical stiffness and mass effects on the orbiter. A vigorous dynamic test program was planned that included not only the 1/4-scale model, but also a horizontal GVT (HGVT) performed on the orbiter by itself and a mated vertical GVT (MVGVT) performed on the four-body vehicle to validate the mathematical models. 
The MVGVT was performed between the summers of 1978 and 1979 at MSFC in TS 4550. The vehicle test configuration necessitated modifications to the test stand and the HDS used for Saturn V testing (Figures 3 and 4). TS 4550 was designed to test vehicles larger than the Saturn V, specifically a vehicle with a 50-foot diameter and about the same height as Saturn V, so the interior of the stand was adequately sized to accommodate Shuttle dynamic testing. ${ }^{16}$ Three columns and all horizontal and vertical connectors to them were removed. Five new columns were added and the derrick crane was relocated. The door was widened to allow the orbiter to be emplaced in one piece.

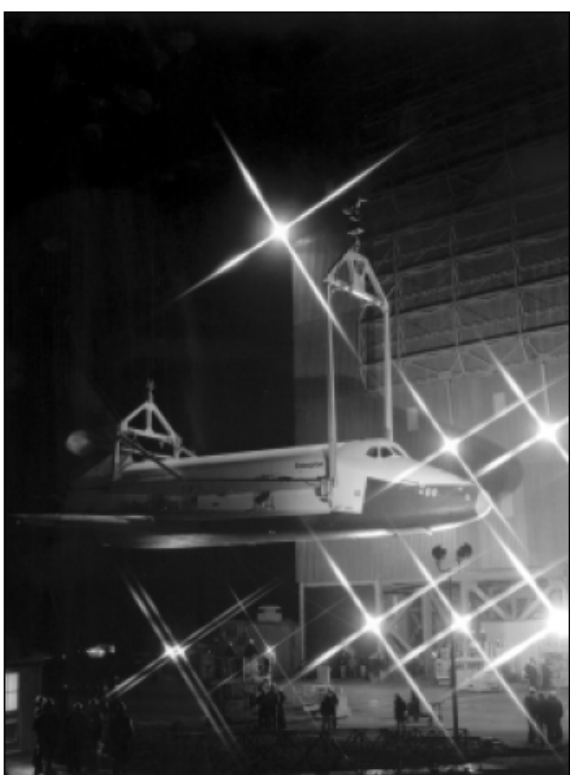

Figure 3 - Orbiter Prepared for Lift into TS 4550

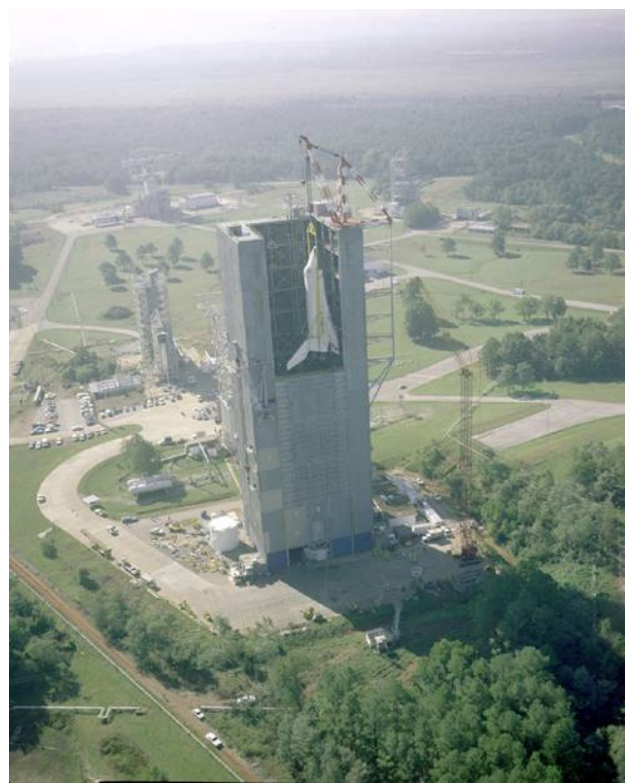

Figure 4 - Orbiter Lifted into TS 4550

The Saturn-era HDSs were used to provide the simulated free-free condition representing free flight. To save cost, adapter frames were developed for the Saturn-era HDSs. These adapter frames required removing the SRB nozzles, as the weight of these components was compensated by the adapter frames.

Interfaces between the ET-SRB and the ET-orbiter (Figure 5) were of prime importance and were heavily instrumented. The ET also required extra instrumentation to adequately characterize and understand the tank, sidewalls, bulkhead and sump areas. The MVGVT used 320 channels of accelerometers, 30 channels of strain gauges, 40 channels of force transducers, 10 channels of pressure transducers, and 9 channels of rate gyros. ${ }^{17}$

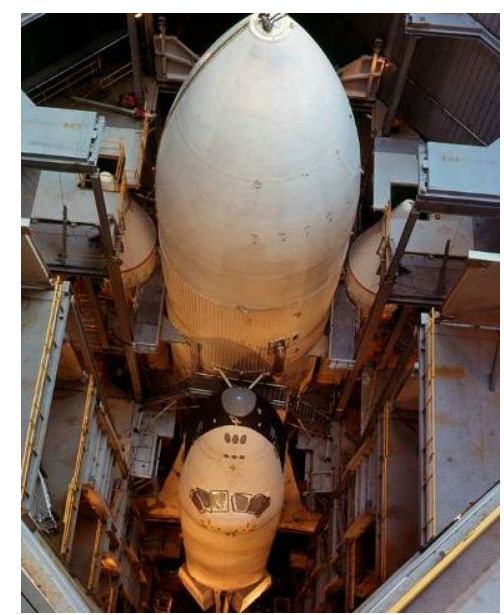

Figure 5 - Orbiter and External Tank in TS 4550 
The MVGVT shakers were either rigid or suspended 150 foot-pound and 1,000 foot-pound electrodynamic units. There were no natural frequencies lower than 100 hertz. The suspended shakers were free pendulums with a maximum frequency of 0.5 hertz. ${ }^{18}$

During MVGVT, sinusoidal excitation was applied to the vehicle by driving shakers located to excite and isolate all significant symmetrical and asymmetrical vibration modes. The transverse excitation range was 1.5 to 30.0 hertz; the longitudinal excitation range was 1.5 to 50.0 hertz.

A new data system was designed and installed, the Shuttle Modal Test and Analysis System (SMTAS). The SMTAS was digital system capable of maintaining modal excitation control, acquiring modal response data and processing, and displaying real-time data. Off-line, the SMTAS could perform data transformation, math model matrix loading, mode shape, frequency, generalized mass, damping, calculations and modal orthogonality checks. ${ }^{19}$ The SMTAS provided control for 24 shaker channels capable of driving 38 shakers. ${ }^{20}$

The vehicle was tested in five configurations during the MVGVT, two for the four-body vehicle and three for the two-body vehicle (Figure 6). The four-body vehicle consisted of the orbiter, two solid rocket boosters (SRBs) and the external tank (ET). This was tested at lift-off and pre-SRB separation (burn-out) vehicle configurations. The two-body vehicle consisted of the orbiter and ET. This was tested at start of boost, mid-boost and end of boost vehicle configurations.
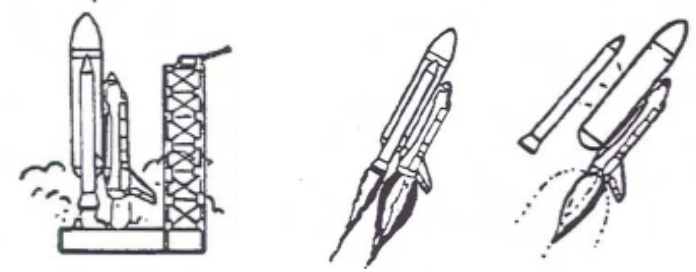

Figure 6 - Shuttle MVGVT Test Configurations

Results of the MVGVT generally showed mode shapes and frequencies below 10 hertz to be good. Frequencies between 10 to 20 hertz ranged from good to fair. Frequencies greater than 20 hertz ranged from good to poor. User frequencies of interest were below 10 hertz, so the structural dynamic models were judged adequate for flight certification.

Major test results identified local resonances in the SRB rate gyros. These resonances corrupted sensor signals. If they had occurred during flight, they would have caused loss of the sensor. Anomalies were also observed in the orbiter side-mounted rate gyros.

Overall, structural damping data ranged from 0.1 percent to greater than 10 percent. Average modal damping was between 1 percent and 3 percent. This damping data was invaluable in the flight certification stability margins. ${ }^{21}$

The following table is a summary of the major findings and likely consequences found during the Space Shuttle MVGVT. $^{22}$

\begin{tabular}{|l|l|l|}
\hline \multicolumn{1}{|c|}{ Problems Discovered } & \multicolumn{1}{c|}{ Hardware Impacted } & \multicolumn{1}{c|}{$\begin{array}{c}\text { Consequences if Not } \\
\text { Discovered }\end{array}$} \\
\hline $\begin{array}{l}\text { SRB-mounted rate gyros } \\
\text { exhibited abnormally high } \\
\text { transfer functions. The rate } \\
\text { gyros mounted on the forward } \\
\text { SRB ring frames resonated at } \\
\text { local frequencies and high gains } \\
\text { that were critical to flight } \\
\text { controls. }\end{array}$ & $\begin{array}{l}\text { Structural redesign was required } \\
\text { to stiffen the SRB ring frame, } \\
\text { which raised the local resonant } \\
\text { frequencies and reduced the gain. }\end{array}$ & $\begin{array}{l}\text { Flight control instability and } \\
\text { possible loss of vehicle. }\end{array}$ \\
\hline $\begin{array}{l}\text { Axial Space Shuttle Main } \\
\text { Engine (SSME) frequencies and } \\
\text { mode shapes did not correlate } \\
\text { with pre-test analysis. A half } \\
\text { shell dynamic math model using } \\
\text { symmetry was used in pre-test } \\
\text { analysis. }\end{array}$ & $\begin{array}{l}\text { A new three dimensional } \\
\text { asymmetric math model of the } \\
\text { SSME engines and thrust } \\
\text { structure was required. No } \\
\text { hardware changes necessary. }\end{array}$ & $\begin{array}{l}\text { Pogo stability analyses would } \\
\text { have been suspect. }\end{array}$ \\
\hline
\end{tabular}




\begin{tabular}{|c|c|c|}
\hline Problems Discovered & Hardware Impacted & $\begin{array}{c}\text { Consequences if Not } \\
\text { Discovered }\end{array}$ \\
\hline $\begin{array}{l}\text { Test rate gyro values showed } \\
\text { greater response variations } \\
\text { than analysis. Response } \\
\text { variations between the Rate Gyro } \\
\text { Assemblies (RGAs) were much } \\
\text { larger than those used in the } \\
\text { analytical studies in determining } \\
\text { the Redundancy Management } \\
\text { (RM) trip levels. }\end{array}$ & $\begin{array}{l}\text { RM software trip levels and cycle } \\
\text { counter levels were increased. } \\
\text { The fault isolation routine was } \\
\text { modified to inhibit kicking out } \\
\text { RGAs and ACCs after first sensor } \\
\text { failure. }\end{array}$ & $\begin{array}{l}\text { Flight control instability and } \\
\text { possible loss of vehicle. }\end{array}$ \\
\hline
\end{tabular}

The Space Shuttle was the first crewed NASA spacecraft to fly humans on its inaugural launch. Results of the dynamic testing during the MVGVT were critical to the decision to launch the vehicle without first performing unmanned flight tests. Dynamic testing continued, however, through the first five flights, all crewed. Clearly the verification of vehicle mathematical models was vital to the successful first flight and the eventual assessment to declare the Shuttle ready for crewed flight. Without this test data to verify the models, confidence to launch humans on the first flight of the vehicle would have been greatly reduced.

\section{Ares}

In 2005, NASA began work on the Constellation Program to return humans to the Moon and build a permanent outpost there as a stepping stone to exploring Mars. The Ares Projects within the Constellation Program are responsible for developing, building and testing the Ares I and Ares V launch vehicles.

The Ares I crew launch vehicle will lift the Orion crew module to low Earth orbit. Ares I is an in-line, two-stage vehicle. Ares I is 325 feet tall, weighs approximately two million pounds at launch, and is capable of lifting 56,200 pounds into low Earth orbit. Ares I has two missions: carry up to six crew (or cargo) to the International Space Station or carry four astronauts to low Earth orbit for rendezvous with Ares V for missions to the Moon. The first stage is a five-segment solid rocket booster based on the heritage Space Shuttle SRB design, and, like the Shuttle SRBs, is reusable. The second stage, or Upper Stage, is powered by the J-2X engine, based on the Saturn secondand third-stage J-2 engine. The Orion crew module sits atop the second stage.

The Ares V cargo launch vehicle will be a heavy-lift vehicle designed to launch cargo and rendezvous with

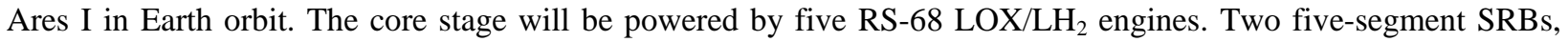
like the first stage of Ares I will also provide launch power. The second stage, or Earth departure stage (EDS), will be powered by the same J-2X engine used for the Ares I second stage. The Altair lunar lander is the payload.

Ares V's mission is to lift Altair and other cargo aboard the Earth departure stage to low-Earth orbit where it will rendezvous with the Orion crew module prior to its journey to the moon. Ares V will be 381 feet tall, weigh 8.1 million pounds at launch, and will be capable of lifting about 414,000 pounds into low Earth orbit and 156,700 pounds to lunar orbit.

Plans to perform the Ares I Integrated Vehicle GVT (IVGVT) began in early 2006. The models correlated from IVGVT test data will support the Ares I Design Certification Review (DCR) in July 2014. The DCR supports the first crewed launch of the Ares I/Orion vehicle planned for September 2014. The detailed schedule is depicted in Figure 7, below. 


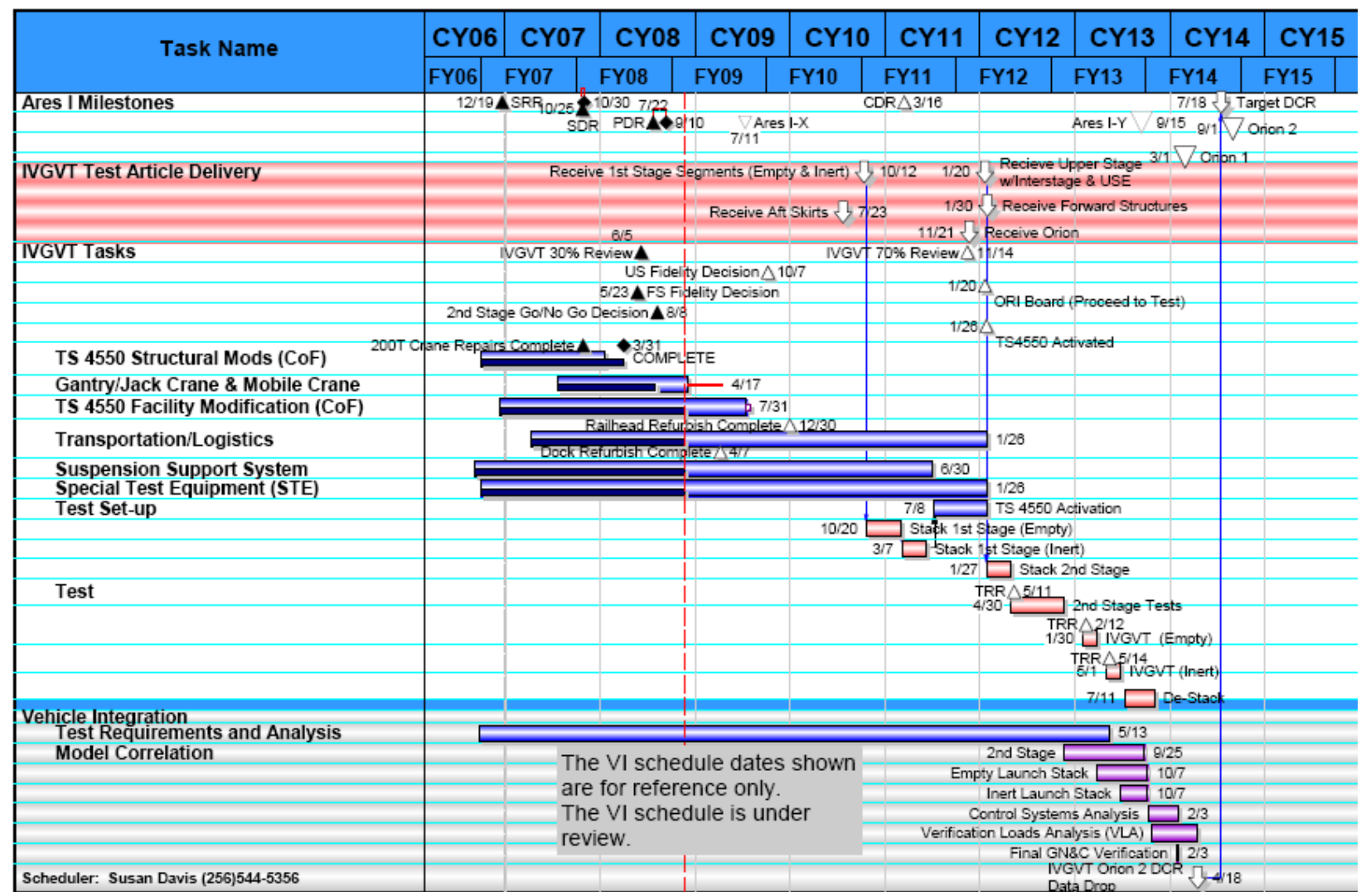

Figure 7. The Ares IVGVT schedule shows most of its work being completed between 2011 and 2013.

After more than 25 years since the Space Shuttle MVGVT, TS 4550 is being repaired and modified to conduct the Ares I IVGVT (Figure 8). In 1987, the United States Department of the Interior's National Park Service designated TS 4550 a national historic landmark.
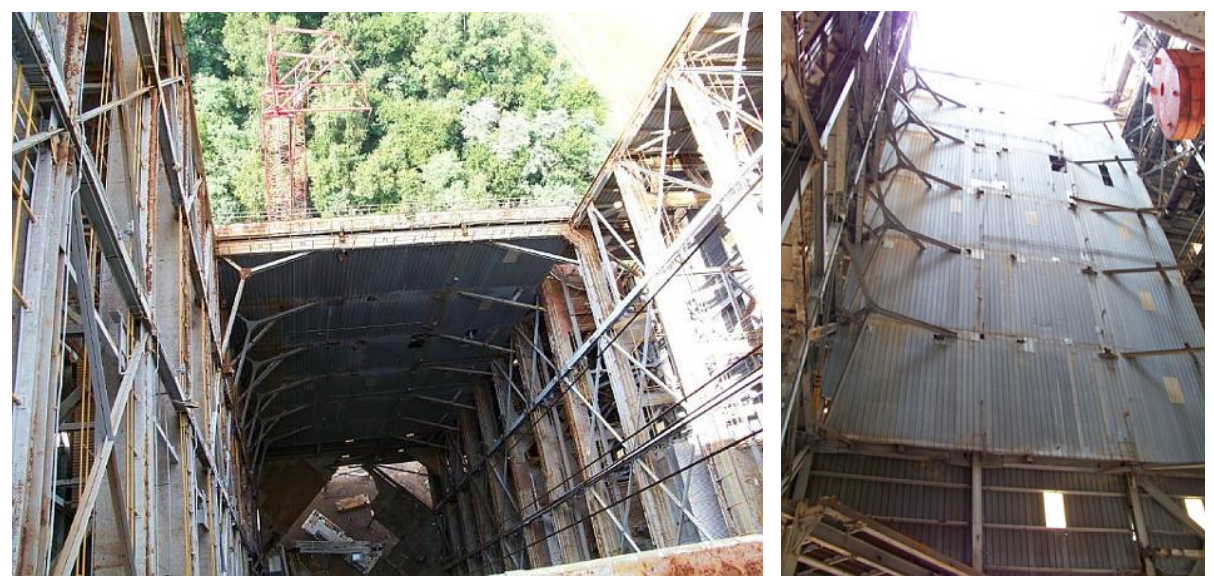

Figure 8. TS 4550 Preparing for IVGVT.

Because of its mothball state since Shuttle-era MVGVT, Test Stand 4550 was inspected and all necessary structural repairs made to bring it up to safety and IVGVT facility requirements. The 200-ton capacity derrick crane on the roof of TS 4550 underwent inspection and load testing. Upgrades and repairs to the 200-ton capacity roof derrick crane include installation a new motor and controls. In March 2008, the crane was used to remove the roof panels and lower the door for the first time since the MVGVT. The Shuttle-era platforms and Special Test Equipment (STE) have been removed and additional equipment is being installed to meet current safety codes and future operational needs (Figure 9). 

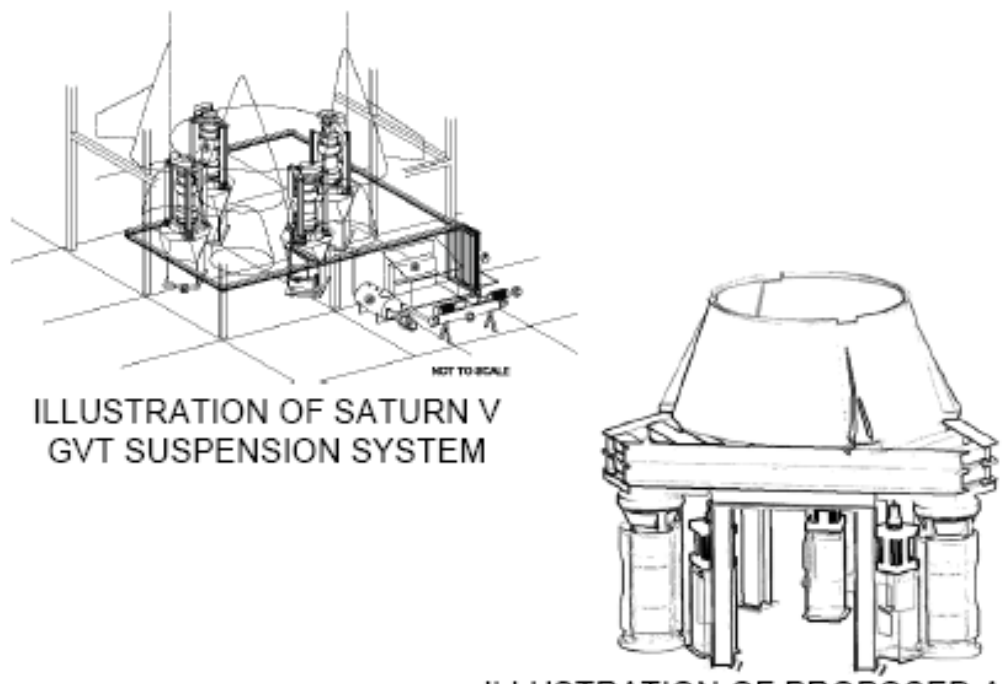

ILLUSTRATION OF PROPOSED ARES

GVT SUSPENSION SYSTEM

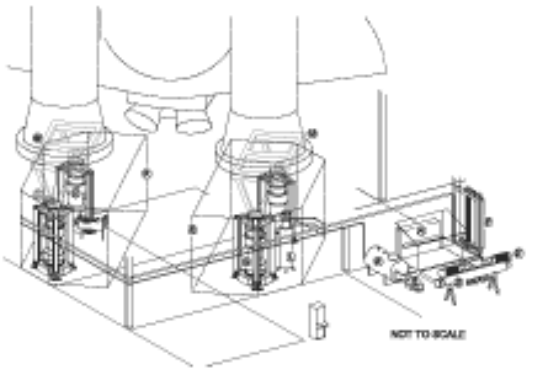

ILLUSTRATION OF SHUTTLE GVT SUSPENSION SYSTEM

Figure 9. Since the 1960s, Test Stand 4550's HDS has been adapted to support a variety of vehicles and test positions.

The platforms will be replaced with mast climbers (Figure 10) that provide ready access to the test articles and can be moved easily to support different test positions within the test stand (Figure 9). IVGVT is using mast climbers instead of building numerous individual test article access platforms. The mast climbers allow almost unlimited vertical access to the test article from the First Stage Aft Skirt to the top of the Orion LAS.
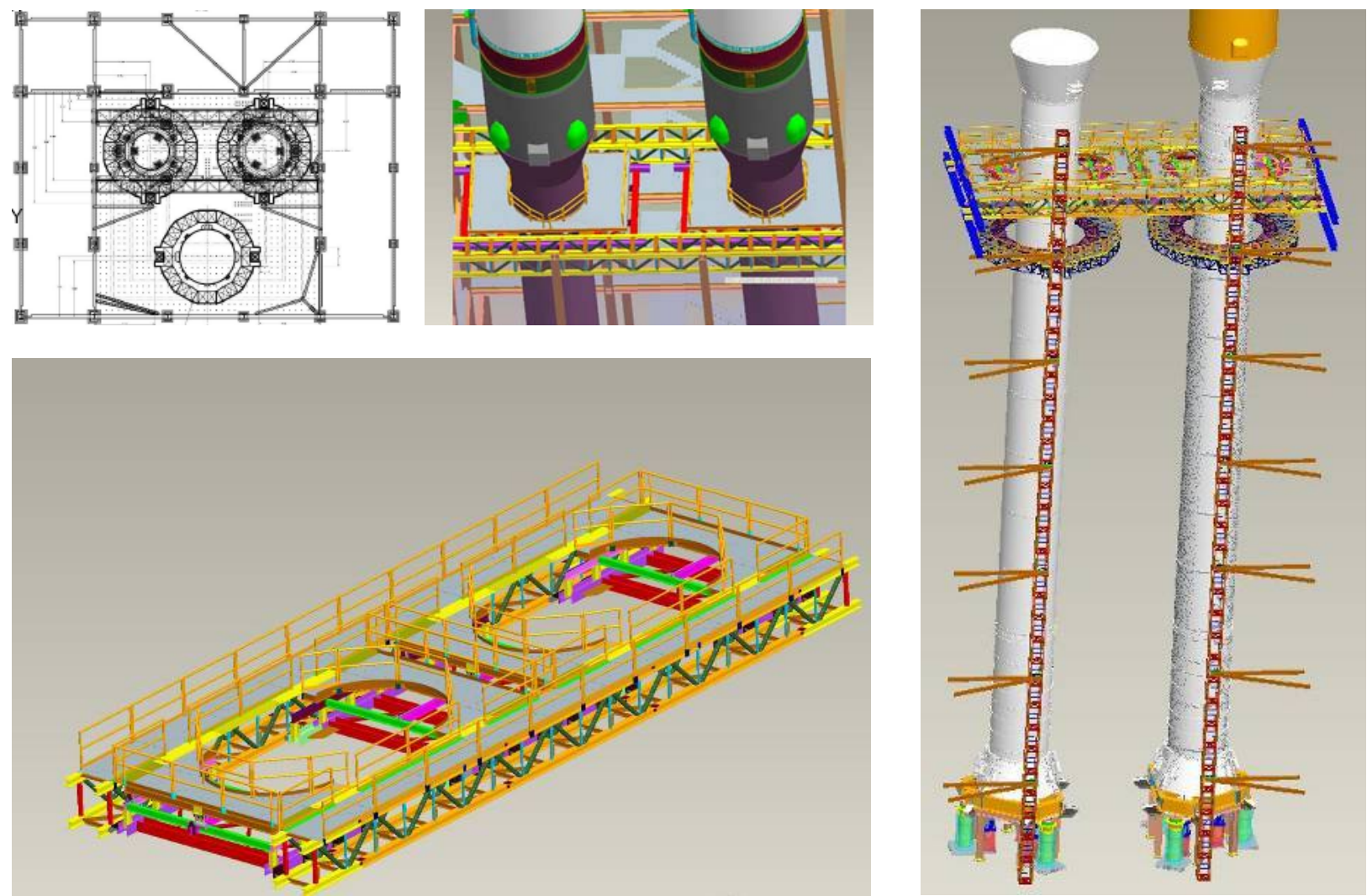

Figure 10. Test positions and mast climber concepts for TS 4550. 
The Upper Stage IVGVT test article will be shipped to Redstone/MSFC by NASA barge (Figure 8), from MAF [near New Orleans, LA] and move by convoy to TS 4550.

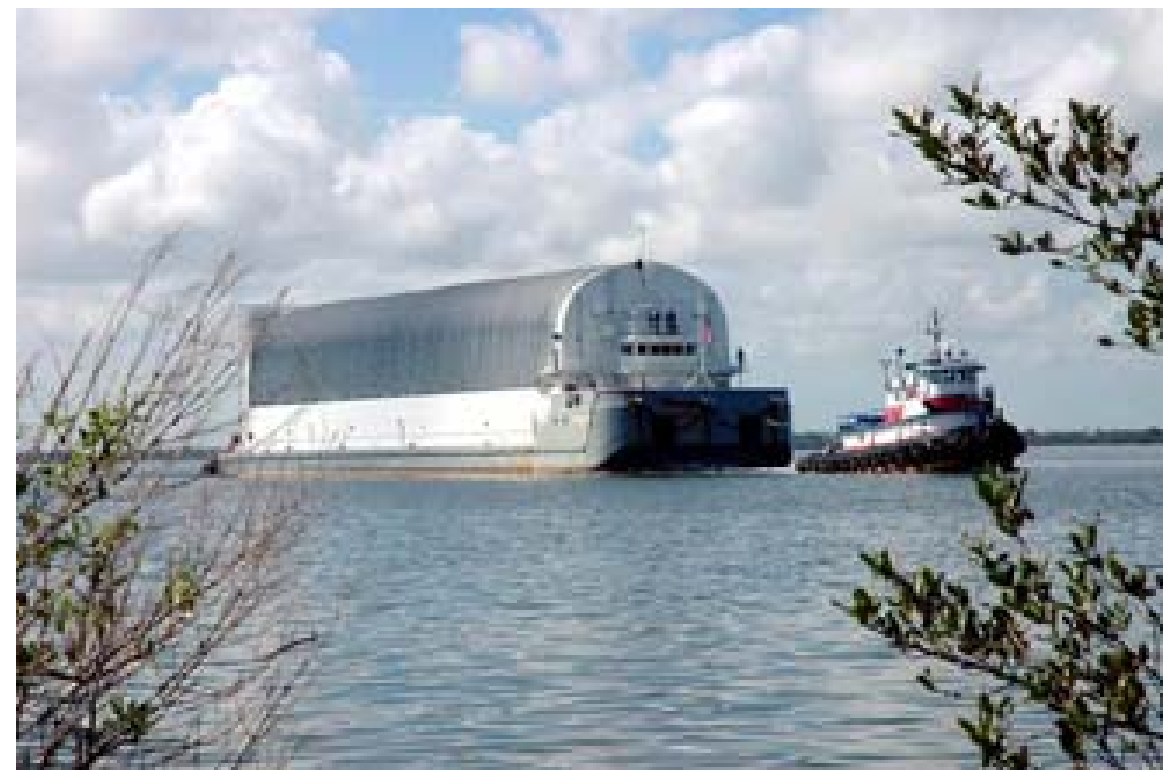

Figure 11. NASA will use the Space Shuttle's external tank barge to deliver the upper stage IVGVT unit.

The Orion IVGVT test article will be shipped via the "Super Guppy" cargo aircraft to the Redstone Arsenal airfield and moved by convoy to TS 4550 (Figure 10). Some Orion hardware will travel to TS 4550 from Glenn Research Center's Plum Brook facility in Ohio and some from Langley Research Center in Virginia.

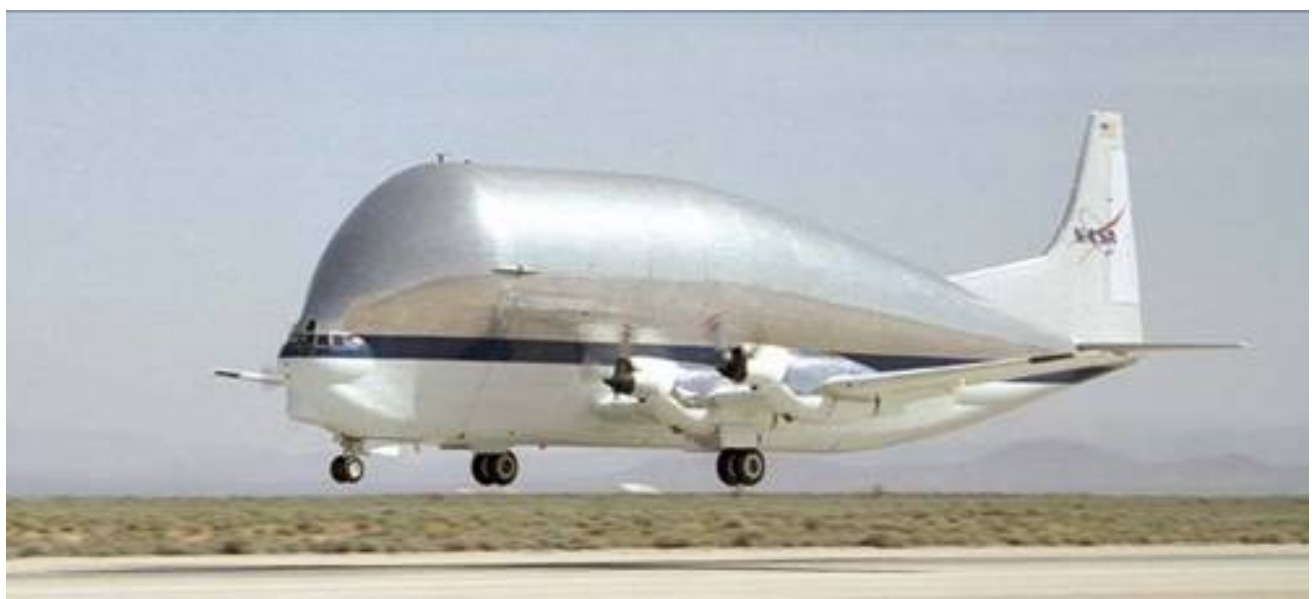

Figure 12. The Super Guppy was first developed to transport vehicle components of the Apollo Program.

Ground Support Equipment (GSE) is an important aspect of IVGVT. GSE is required to unload test article hardware at the entry point to MSFC; transport it to TS 4550 from the entry point; stack, destack, and relocate hardware in the three Test Positions in TS 4550 (Figure 12). Two new cranes are being procured: a jack/gantry crane and a mobile crane to aid in moving the test articles both at the test stand and at the new Redstone Arsenal/MSFC railhead where First Stage segments will be received. The First Stage will arrive from ATK in Utah in a one-train shipment consisting of 10 railcars and move by convoy to TS 4550 . The gantry has been procured and has arrived at MSFC; the mobile crane has been procured, but has not been delivered yet.

The GSE also will stage the hardware outside TS 4550 and at other MSFC locations and after completion of the test, the organizations supplying the hardware for the test will be responsible for its disposition hardware from TS 4450. Hundreds of GSE items are required for IVGVT. GSE is generally being provided to IVGVT from the Ares I Elements and Orion. 


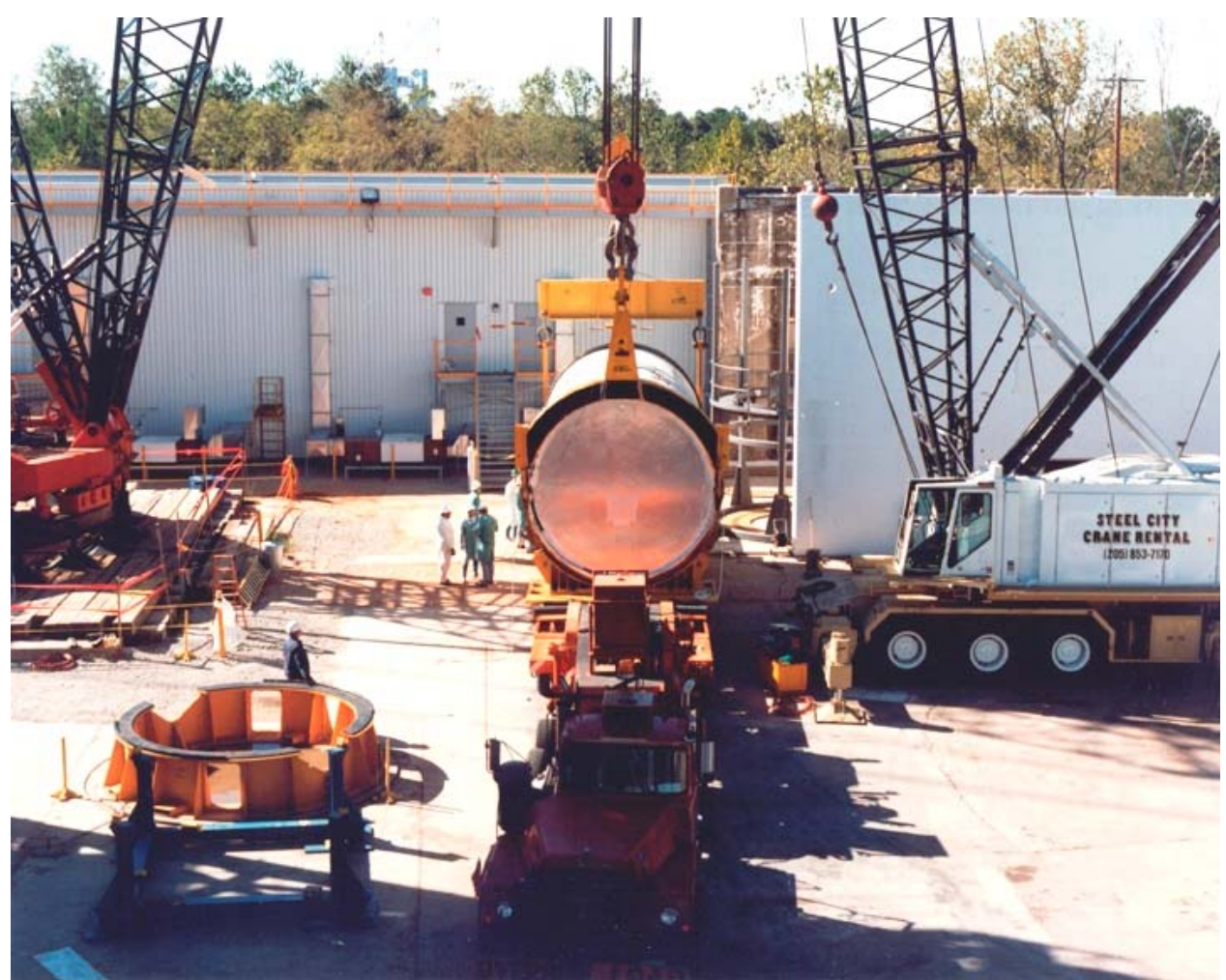

Figure 13. A variety of cranes will be used to move IVGVT hardware from transportation facilities to Test Stand 4550.

The design for a new electrical system and for safety modifications has been developed and released. Work on these modifications began in the fall of 2008 and is scheduled to complete in the summer of 2009.

Phase I of developing the test requirements for the IVGVT was completed in January 2008. This phase consisted mostly of Beam-Model development and exploring frequency ranges of interest. Phase II is currently underway and was completed in June 2008. The test requirements support development of the IVGVT Test Plan as well as the Special Test Equipment (STE) development and design. A draft Test Plan was submitted for review at the Ares I PDR. STE design is in the preliminary phase, which will continue into Spring 2009.

The HDS used for Saturn and Shuttle are being disassembled and evaluated for use during IVGVT. Progress to date is promising. All three HDS units needed to accomplish IVGVT have been refurbished and are undergoing load testing. A fourth refurbished HDS is a spare. A modular hydraulic powerpack unit has been designed and a contract awarded to build the first of four such units, one unit for each of the three HDS plus one spare powerpack. In parallel with the HDS evaluation, a concept pneumatic system is being explored. A decision on which suspension to use for IVGVT will be made in May 2010. 

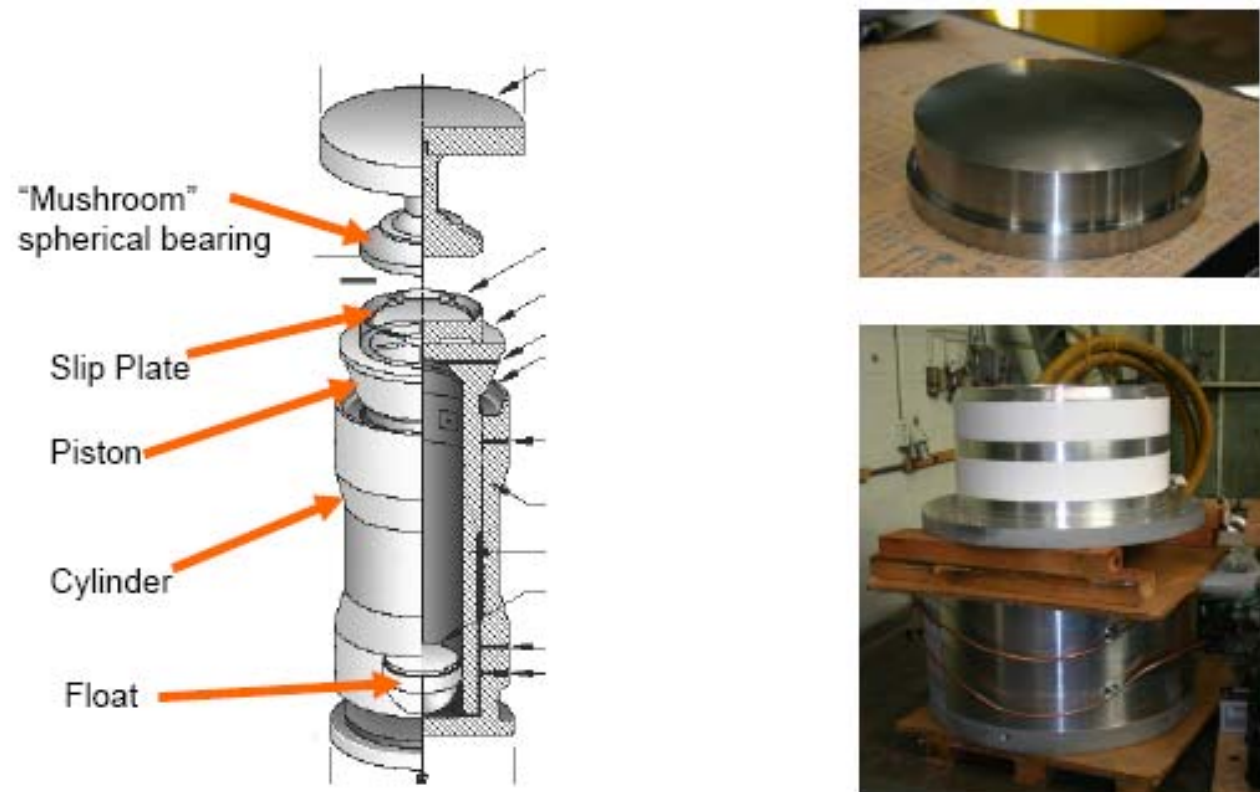

"Rocker"

spherical bearing

prototype

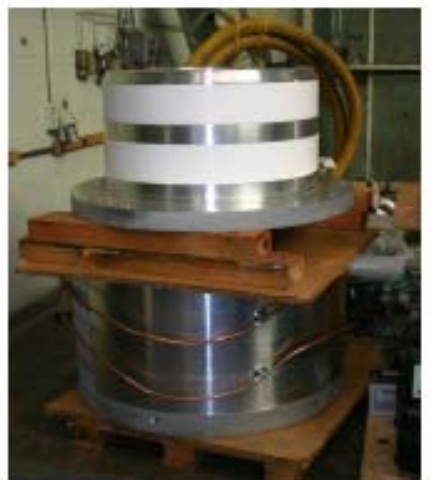

Pneumatic

suspension system

prototype

Figure 14 - While both hydrodynamic and pneumatic alternatives are being explored for the HDS, a hybrid system is also being considered.

Hydraulic shakers will be used to excite the vehicle at locations to be determined by pre-test analysis. The FITO team anticipates that the majority of shaker locations will be near the base of the vehicle. Testing will include both random and sinusoidal excitation, sine sweeps, and characterizing any non-linearities.

IVGVT test article instrumentation will consist primarily of tri-axial accelerometers. At this time in test planning and analysis, it is not known if strain gauges or other instrumentation will be required, nor has the requirements development process identified quantity or location for IVGVT test article instrumentation required by the Ares I Elements or Orion. Some facility instrumentation will be required to fill, drain, and vent the US tanks and purge the FS inert propellant stack. The facility instrumentation and control list is under development. The phase II requirements development will produce a preliminary instrumentation plan in the summer of 2009.

The current plan is that the Ares I IVGVT will test six configurations in three test positions in TS 4550 (Figure 15). TS 4550 Test Position 1 consists of the entire launch stack at liftoff representing Gross-Lift-Off-Weight (GLOW) or total launch stack mass at $\mathrm{T}=0$ using inert First Stage segments and propellant simulants throughout the vehicle. Test Position 2 consists of the entire launch stack at First Stage burn-out (using empty First Stage segments) just before FS and US stage separation. Transfer function measurements will be made during all test configurations. Position 3 consists of the Ares I Upper Stage with Orion. Test Position 3 will be used to test four configurations after US stage separation. These are J-2X ignition, post Launch Abort System (LAS) jettison, critical slosh mass and J-2X burn-out, also called MECO or Main Engine Cut-Off. 


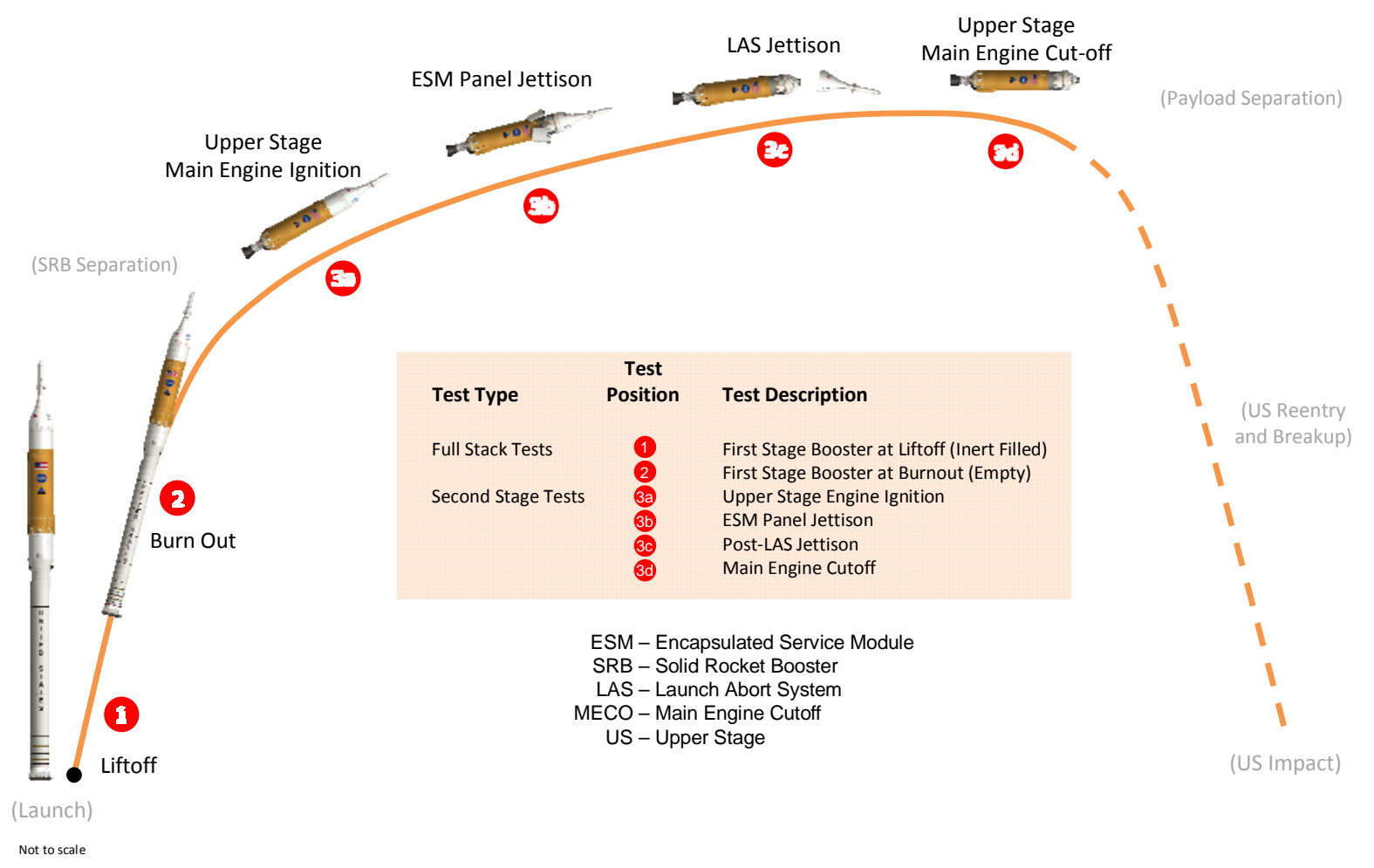

Figure 15 - IVGVT Test Configurations

The Ares IVGVT will be conducted from mid-2012 to mid-2013. It is intended for IVGVT to measure by test the fundamental dynamic characteristics of Ares I during various phases of operation and flight. The final measured results of the IVGVT are clearly dependent on the fidelity of vehicle hardware used during the test and appropriately simulated boundary conditions (BC). A fundamental philosophy of structural dynamic testing is to have as few differences between the test article and the flight article as possible. For accurate testing and model correlation and acceptable levels of uncertainty, both the test and flight configurations must be known and differences understood fully.

To accurately represent the properties of the Ares I flight vehicles, the Ares I IVGVT will be conducted on a test article built to flight-equivalent specifications. The First Stage (FS) Element Office is providing one set of first stage segments that will return to flight inventory at the conclusion of IVGVT. The second set of first stage segments containing inert solid propellant will not likely return to flight inventory. The FS IVGVT test article will not have a first stage nozzle for IVGVT but a mass simulator but have an Aft Skirt. The Ares Upper Stage Engine (USE) Element will provide IVGVT the first US manufactured at MAF. The Ares Upper Stage Engine (USE) Element will provide the US Element will a dynamic mass simulator provide by the J-2X engine contractor. Orion currently plans provide an Orion Ground Test Article (GTA) to IVGVT.

Mass simulators of certain components may be used for flight-quality components that are not available in the scheduled test timeframe, provided there is sufficient technical rationale to do so. As a general "rule-of -thumb" IVGVT test article items of less than 25 pounds will be mass simulators. IVGVT and Ares Vehicle Integration analysts will determine which hardware may be mass simulators. Mass simulators will have the correct mass, centerof-gravity, and products of inertia. The analysts will approve test article configuration prior to beginning a test and approve break-of-configuration before hardware removal and moving on to the next test in a series.

The primary objectives of the IVGVT will be calibrating the Finite Element Models (FEM) for the system and each flight element. These FEMs are then used for the vehicle certification analysis.

Test objectives pertaining to flight control objectives are to obtain:

1) Natural vehicle mode shapes, frequencies, generalized mass, and damping characteristics and coefficients which are used in the stability equations; and

2) Amplitude and phase response of the elastic vehicle and transfer functions from thruster locations to all flight control sensor locations. 
Structural dynamic test objectives are to obtain:

1) Mode shapes, frequencies, and damping to be used as the reference for test calibrated CLV configuration models that form the basis of final verification loads and GN\&C controls analysis; and

2) Experimental non-linear characteristics of vehicle configurations by exciting the test specimen at different force levels.

Ares V planning and early design is in work at this time, but at a very low level of effort as the Constellation program focus is on Ares I/Orion development and launch. However, initial planning for the Ares V IVGVT has been ongoing. This planning consists primarily of facility studies and a preliminary schedule for long-range budget planning purposes. Ares V efforts are expected to increase in fiscal year 2010, after Space Shuttle retirement.

\section{Summary and Conclusions}

NASA has conducted dynamic tests on each of its major launch vehicles during the past 45 years. Each test has provided invaluable data to correlate and correct analytical models used to predict structural responses to differing dynamics for these vehicles. With both Saturn V and Space Shuttle, hardware changes were also required to the flight vehicles to ensure crew and vehicle safety.

The Ares I IVGVT will undoubtedly provide similar valuable test data to support successful flights of the Constellation Program. The IVGVT will provide test determined natural frequencies, mode shapes and damping for the Ares I. This data will be used to support controls analysis by providing this test data to reduce uncertainty in the models. The value of this testing has been proven by past launch vehicle successes and failures. Performing dynamic testing on the Ares vehicles will provide confidence that the launch vehicles will be safe and successful in their missions. In addition, IVGVT will provide the following benefits for the Ares rockets:

- IVGVT data along with Ares development flights like Ares I-X, Ares I-Y, Ares I-X Prime, and Orion1 or others will reduce the risk to the Orion-2 crew. IVGVT will permit anchoring the various analytical and operational models used in so many different aspects of Ares operations.

- IVGVT data will permit better understanding of the structural and GN\&C margins of the spacecraft and may permit mass savings or expanded day-of-launch opportunities or fewer constraints to launch.

- Undoubtedly IVGVT will uncover some of the "unknown unknowns" so often seen in developing, launching, and flying new spacecraft vehicles and data from IVGVT may help prevent a loss of vehicle or crew.

- IVGVT also will be the first time Ares I flight-like hardware is transported, handled, rotated, mated, stacked, and integrated.

- Furthermore, handling and stacking the IVGVT launch vehicle stacks will be an opportunity to understand certain aspects of vehicle operability much better (for example, handling procedures, touchlabor time to accomplish tasks, access at interfaces, access to stage mating bolts, access to avionics boxes, access to the Interstage, GSE functionality, and many other important aspects of Ares I operability).

All of these results will provide for better vehicle safety and better stewardship of national resources as NASA begins its next phase of human space exploration.

\section{References}

Kabe, Alvar, "Design and Verification of Launch and Space Vehicle Structures,” AIAA-98-1718 (April 1998).

Kabe, Alvar, Loads Analysis Model Verification and Validation (Aerospace Corporation).

Boeing Changes Delta III Control Software, Boeing News Release (October 1998).

De Selding, Peter B., "Harsh Report Issued on Ariane 5 Failure,” Space News (January 2003).

Covington, Wayne R., Seaholm, Norman A., "Saturn V Dynamic Test Program,” Transactions of 1967 National Symposium on Saturn V/Apollo and Beyond, Huntsville, AL (June 12-14, 1967).

Ibid.

Ibid.

Ibid.

Von Pragenau, George L. "Free Flight Simulated on Ground with Apollo Saturn V Space Vehicle,"

AIAA/JACC Guidance and Conference, Seattle, WA, (August 15-16, 1966). 
10 Grimes, P.J., McTigue, L.D., Riley, G.F. and Tilden, D.I., “Advancements in Structural Dynamic Technology Resulting from Saturn V Programs, vol. I, NASA Contractor Report (June 1970).

11 Covington, Wayne R., Seaholm, Norman A., "Saturn V Dynamic Test Program,” Transactions of 1967 National Symposium on Saturn V/Apollo and Beyond, Huntsville, AL (June 12-14, 1967).

12 Ibid.

13 Ibid.

14 Ibid.

15 Ivey, Edward W., "Mated Vertical Ground Vibration Test,” NASA Technical Memorandum (July 1980).

16 Dyer, Henry C., "Orbiter Structure and Mated Ground Vibration Tests,” Presentation to SP-Manager (November 29, 1972).

17 Ivey, 8.

18 Ibid.

19 Ibid.

20 Ibid.

21 Modlin, Thomas C., Jr., Zupp, George A., Jr., "Shuttle Structural Dynamics Characteristics, the Analysis and Verification,” Space Shuttle Technical Conference, Houston, Texas (June 1983).

22 Ivey, 85. 